\section{$\underset{\substack{\text { hommes } \\ \text { \& migrations }}}{ }$}

\section{Hommes \& migrations}

Revue française de référence sur les dynamiques

migratoires

$1313 \mid 2016$

1983, le tournant médiatique

\title{
Collectif, Dépasser la frontière
}

Ker Editions, 2015, 155 p., $10 €$

\section{Mustapha Harzoune}

\section{(2) OpenEdition}

12 Journals

\section{Édition électronique}

URL : http://journals.openedition.org/hommesmigrations/3608

DOI : 10.4000/hommesmigrations.3608

ISSN : 2262-3353

\section{Éditeur}

Musée national de l'histoire de l'immigration

\section{Édition imprimée}

Date de publication : 1 janvier 2016

Pagination : 173-174

ISBN : 978-2-919040-34-6

ISSN : 1142-852X

Référence électronique

Mustapha Harzoune, "Collectif, Dépasser la frontière », Hommes \& migrations [En ligne], 1313 | 2016, mis en ligne le 17 juin 2016, consulté le 24 septembre 2020. URL : http://journals.openedition.org/ hommesmigrations/3608; DOI : https://doi.org/10.4000/hommesmigrations.3608 
couleur et de la fierté ì l'immigration portugaise, et singulièrement ì la mère et ìson fils, Max se moque, lui, d'une révolution pacifique et goûte encore moins le retour en grâce du mari défunt, devenu héros nationat.

Olivio visitera sa famille au Portugal. tì, itsera exclusivementle fils deson père.H ressentira la honte de décevoir, la honte de n'être pas ì la hauteur du souvenir de ce père, la honte d'être un enfant sensible, bon élève, doué, différent, irré ductible aux "nous "dans lesquels, en France comme au Portugal, on voudrait l'enfermer.Avec Ahmed, ils apprennent ì devenir les héros de leur propre vie, loin des trajectoires imposées et des injonc tions. "Nous n'avions rien à nous repro cher, Ahmed et moi, et pourtant nous nous comportions comme des proies que l'on traque. "Restent les tentatives d'évasion. Auême ratées. A..H.

\section{Collectif}

\section{Dépasser la frontière}

Ker Editions, 2015, 155 pages, $10 €$

Que pensent nos concitoyens de la notion de "frontières » ? Ceci n'est ni un sondage, ni une étude reposant sur un échantillon précis à défaut d'être représentatif. Non, il s'agit là de l'initiative de modestes mais indispensables bibliothèques à laquelle, lecteurs et usagers, ont répondue : un concours d'écriture transfrontière organisé par les bibliothèques de Beauraing, Bièvre, Doische, Rochefort et Wellin en Belgique et Givet dans les Ardennes. Douze contributions ont été retenues, douze lauréats qui connaissent le privilège d'être publiés. Douze textes qui croisent des univers singuliers, des ambiances plus ou moins denses, des écritures tantôt scolaires tantôt originales, l'épaisseur de la démonstration y croise le trait, plus subtil et léger, de la fiction. II n'est pas question ici de réfugiés, encore moins d'une Europe en proie à un délire obsidional. Non. "Dépasser la frontière ", car tel est le thème retenu, est d'abord et souvent une expérience personnelle, individuelle, intime même, dont l'écho peut certes retentir au delà de la périphérie des existences. De quoi s'agit-il ? D'un traumatisme de l'enfance dont il faudra bien, d'une manière ou d'une autre, se libérer. De «frontières qui n'existent qu'à l'intérieur " de ce comptable retranché, tel un "autiste " derrière un mur bâti comme un refuge, mais qui pourrait céder par amour D'espace inventé, dans lequel on s'enferme - dans son " ghetto " comme l'a montré Eddy L.Harris (Harlem, Liana Lévi, 2007) - au point d'en devenir l'esclave : « le jardin de Monsieur Victor, c'est son domaine privé (...) sa dernière raison de vivre "! Sacralisation subjective d'un espace auquel on a parfois consacré une vie entière de sacrifices. Alors on le protège, on se protège. II y a l'instinct du propriétaire, le souci de l'ordre et de la propreté que les apprentis sorciers de la politique savent exploiter. Quitte à 


\section{LIVRES}

prendre le risque de crever seul derrière sa haie de thuyas! Où quand la propension à clôturer son monde signe l'incapacité à être au monde, aux autres et, in fine, à soi.

Intimité encore quand, par une prouesse littéraire se jouant de la barrière du temps, deux femmes vivant l'une en 1910 l'autre en 2010, se racontent et dialoguent par delà le siècle dans le même carnet. L'enfermement (l'aliénation ?) est au féminin. Anna, femme de 1910 soumise, mariée de force, " enfermée dans une camisole cousue d'or et de soie » et, Émeline, piégée par l'existence, seule pour élever ses deux enfants, qui perd pied. Anna conseille à notre contemporaine de tomber le masque, de ne plus cacher ses faiblesses, de s'ouvrir à soi, à la vie.

La légèreté du propos - voir ce passage de la frontière avec 600 bouteilles de Veuve Clicquot dans le coffre - voisine avec les drames de la maladie, des frontières linguistiques entre un père et son fils, entre régions flamande et wallonne, le drame des frontières sociales dans une région à genoux depuis les fermetures des mines et autres aciéries sur fond d'histoire migratoires. Drame encore lorsque les frontières claquent sur l'amour en contrebande d'une jeune fille du village et de Djamel un Algérien. Sur fond de guerre d'Algérie, partir devient un acte de résistance.

Et si la frontière, avant d'être un objet d'étude historique, politique ou géostratégique était d'abord une attitude individuelle : la capacité de chacun à rester, ou non, en contact, à ne pas se replier dans son petit monde, ses petites pensées, ses petites certitudes, indifférent, quand ce n'est pas hostile, à celles et ceux qui nous entoure. La frontière à hauteur d'existence et de quotidien : actes invisibles de bravoure, actes désespérés, porte qui claque ou horizon qui recule. "Dépasser la frontière " comme pour mieux être au monde. M. H. 